\title{
PENGARUH THINK PAIR SHARE DISERTAI STANDING BANNER TERHADAP HASIL BELAJAR SISWA SMAN 16 PEKANBARU
}

\author{
Al Khudri Sembiring ${ }^{1)}$ Deni $^{2)}$ \\ ${ }^{1), 2)}$ Pendidikan Biologi FKIP Universitas Lancang Kuning \\ email $^{1)}:$ alkhudri_s@unilak.ac.id \\ email $^{2)}$ : denibringas4@gmail.com
}

\begin{abstract}
ABSTRAK : Penelitian ini bertujuan untuk mengetahui pengaruh model pembelajaran Think Pair Share disertai Standing Banner terhadap hasil belajar siswa pada materi sistem pencernaan manusia kelas XI IPA 2 SMA Negeri 16 Pekanbaru tahun pelajaran 2018/2019. Penelitian ini dilaksanakan pada semester ganjil pada bulan November 2018. Desain penelitian yang digunakan adalah kuasi eksperimen metode the matching only pretest-posttest control group designs, sampel penelitian adalah kelas XI IPA 1 dan kelas XI IPA 2 dengan jumlah masing-masing kelas 30 siswa, yang diambil dengan teknik total sampling. Penggumpulan data dilakukan melaui pretest, posttest, lembar observasi guru dan lembar observasi siswa. Teknik analisis data yang digunakan adalah independent 2 samples $t$-test. Rerata $N$-gain kelas kontrol 0.54 kategori sedang sedangkan kelas eksperimen 0.68 kategori sedang. Hasil uji-t $N$-Gain terdapat perbedaan signifikan antara kelas kontrol dan kelas eksperimen. Berdasarkan hasil penelitian dapat disimpulkan bahwa terdapat pengaruh model pembelajaran Think Pair Share disertai Standing Banner terhadap hasil belajar siswa pada materi sistem pencernaan manusia kelas XI IPA 2 SMA Negeri 16 Pekanbaru tahun pelajaran 2018/2019.

Kata kunci : think pair share, standing banner, sistem pencernan manusia, hasil belajar
\end{abstract}

ABSTRACT : This research was conducted in odd semester in November 2018. The research design used was quasi-experimental matching method only pretest-posttest control group designs, the study sample was class XI IPA 1 and class XI IPA 2 with the number of each class 30 students, taken by total sampling technique. Data collection was done through pretest, posttest, teacher observation sheet and student observation sheet. The data analysis technique used was independent $2 \mathrm{t}$-test samples. The mean $\mathrm{N}$ gain control class was 0.54 medium category while the experimental class was 0.68 medium category. The results of the $N$-Gain $t$-test have significant differences between the control class and the experimental class. Based on the results of the study it can be concluded that there was the influence of Think Pair Share learning model according with Standing Banner on student learning achievement in the human digestive system matery class XI IPA 2 SMA 16 Pekanbaru academic year 2018/2019.

Keywords: think pair share, standing banner, human digestion system, learning achievemment 


\section{PENDAHULUAN}

Pendidikan adalah usaha yang dilakukan dengan sengaja dan sistematis untuk memotivasi, membina,membantu, serta membimbing seseorang untuk mengembangkan segala potensinya sehingga ia mencapai kualitas diri yang lebih baik. Inti pendidikan adalah usaha pendewasaan manusia seutuhnya (lahir dan batin), baik oleh dirinya sendiri maupun orang lain, dalam arti tuntutan agar siswa memiliki kemerdekaan berpikir, merasa, berbicara dan bertindak serta pecaya diri dan penuh rasa tanggung jawab dalam setiap tindakan dan perilaku sehari-hari (Tatang, 2012).

Belajar adalah modifikasi atau memperteguh kelakuan melalui pengalaman (learning is defined as the modification or strengthening of behavior through experiencing). Menurut pengertian ini, belajar merupakan suatu proses, suatu kegiatan dan bukan suatu hasil atau tujuan. Belajar bukan hanya mengingat, akan tetapi lebih luas dari itu, yakni mengalami. Mengajar juga dapat diartikan sebagai: 1) Menyampaikan pengetahuan kepada siswa didik atau murid di sekolah, 2) mewariskan kebudayaan kepada generasi muda melalui lembaga pendidikan sekolah, 3) usaha mengorganisasi lingkungan sehingga menciptakan kondisi belajar bagi siswa, 4) memberikan bimbingan belajar kepada murid, 5) kegiatan mempersiapkan siswa untuk menjadi warga negara yang baik sesuai dengan tuntutan masyarakat, 6) suatu proses membantu siswa menghadapi kehidupan sehari-hari (Hamalik, 2001).

Berdasarkan hasil observasi selama PPL di SMA Negeri 16 Pekanbaru bahwa siswa cenderung tidak terlibat aktif selama proses belajar mengajar berlangsung. hasil belajar siswa kelas XI IPA 2 masih tergolong rendah atau dibawah KKM 78. Sebagian besar siswa berpikir bahwa pelajaran biologi adalah pelajaran yang membosankan karena sulit dibayangkan. Cenderung menghafal dan tidak mau bertanya atau bersikap pasif meskipun sebenarnya belum mengerti materi yang diajarkan oleh guru. Strategi yang digunakan oleh guru untuk mengaktifkan siswa yaitu melibatkan siswa dalam diskusi kelompok. Tetapi strategi tersebut kurang efektif meskipun sudah mendorong siswa untuk berpartisipasi, masih banyak siswa yang diam terpaku 
menjadi penonton, sementara arena diskusi hanya dikuasai sebagian siswa.

SMA Negeri 16 Pekanbaru merupakan SMA yang baru dibangun di daerah rumbai pesisir dengan kondisi siswanya dari lingkungan keluarga dan pergaulanyang berbeda-beda, membuat siswa kurang rasa ingin tahu antara satu dengan yang lainnya. Kondisi tersebut akan mempengaruhi proses pembelajaran apabila tidak segera diatasi, sehingga perlu dibentuk kelompok-kelompok kecil dari latar belakang yang berbeda dengan harapan agar setiap siswa dalam kelompoknya bias saling kerjasama. Dengan demikian, guru perlu menerapkan model pembelajaran think pair share (TPS).

Tujuan dari penelitian ini adalah untuk mengetahui pengaruh penerapan model pembelajaran think pair share(TPS) berbantuan media standing banner terhadap hasil belajar pada sistem pencernaan manusia di kelas XI IPA 2 SMA Negeri 16 Pekanbaru”.

\section{METODE PENELITIAN}

Penelitian ini merupakan penelitian quasi eksperimen (quasi experimental designs) yang bertujuan untuk mengetahui pengaruh variable bebas terhadap variabel terikat, menggunakan metode The Matching Only PretestPosttest Control Group Desain.

Populasi penelitian ini adalah seluruh siswa kelas XI IPA 2 SMA Negeri 16 Pekanbaru yang terdiri 2 kelas.Sebagai sampel diambil 2 kelas dengan menggunakan teknik total sampling yang artinya semua kelas dijadikan sampel (sugiyono, 2015).

Parameter dalam penelitian ini yaitu hasil belajar siswa, aktivitas guru dan aktivitas siswa.

\section{HASIL DAN PEMBAHASAN}

Tabel 1 : Rekapitulasi Uji NormalitasN-Gain

\begin{tabular}{|l|l|l|l|l|}
\hline Kelas & Signifikan & $\alpha$ & Keputusan & keterangan \\
\hline Kontrol & 0.200 & 0.05 & Terima $\mathrm{H}_{0}$ & Normal \\
\hline Eksperimen & 0.200 & 0.05 & Terima $\mathrm{H}_{0}$ & Normal \\
\hline
\end{tabular}

Berdasarkan Tabel 1 hasil uji sedangkan untuk kelas eksperimen normalitas $N$-Gain diperoleh nilai adalah 0.200 keputusan yang diambil signifikan untuk kelas kontrol terima $\mathrm{H}_{0}$ karena signifikan kelas 
control dan kelas eksperimen> 0.05 hal ini berarti data pada kelas control dan kelas eksperimen berdistribusi normal. Selanjutnya dilakukan uji homogenitas data $N$-Gain uji homogenitas ini berguna untuk menguji kehomogen
data.Analisis data homogenitas dengan menggunakan uji levene test. Hasil uji homogenitas pada kelas kontrol dan kelas eksperimen dapat dilihat pada Tabel berikut.

Tabel 24 : Rekapitulasi Homogenitas Uji N-Gain

\begin{tabular}{|c|c|c|c|c|}
\hline Jenis data & Based on trimmed mean & $\alpha$ & Keputusan & Keterangan \\
\hline N-gain & 0.094 & 0.05 & Terima $\mathrm{H}_{0}$ & Homogen \\
\hline
\end{tabular}

Berdasarkan Tabel 24 Hasil uji homogenitas data $N$-Gain diperoleh nilai based on trimmed mean 0.094 dari data tersebut keputusan yang diambil adalah terima $\mathrm{H}_{0}$ karena nilai based on trimmed mean pada levene test 0.094> 0,05 maka dapat dikatakan bahwa $N$ Gain kelas kontrol dan kelas eksperimen berasal dari varian yang homogen.
Setelah data $N$-Gain kelas kontrol dan kelas eksperimen diketahui normal dan homogen maka dilakukan uji-t untuk mengetahui apakah data berbeda signifikan atau tidak. Analisis data $u j i-t$ ini yang dilihat adalah nilai signifikan yang dibandingkan dengan taraf kepercayaan (a) 0.05 maka data berbeda signifikan atau sebaliknya. Hasil uji-t data $N$-Gain dapat dilihat pada Tabel 4

Tabel 25 : Rekapitulasi Hasil Uji-t data $N$-Gain

\begin{tabular}{|l|l|l|l|l|}
\hline Jenis data & Sig.(2-tailed) & $\alpha$ & Keputusan & Keterangan \\
\hline $\mathrm{N}$-gain & 0.000 & 0.05 & Tolak $\mathrm{H}_{0}$ & Berbeda Signifikan \\
\hline
\end{tabular}

Berdasarkan Tabel 25 dapat dilihat hasil uji-t untuk data $N$-Gain kelas kontrol dan kelas eksperimen dengan $(a)=0.05$ diperoleh nilai Sig (2tailed) 0.000 dari hasil tersebut keputusan yang diperoleh adalah tolak

\section{KESIMPULAN}

Berdasarkan penelitian yang telah dilakukan di SMA Negeri 16
$\mathrm{H}_{0}$ yang artinyadata berbeda signifikan, karena nilai Sig (2-tailed) $0.000<0.05$ hal ini menunjukkan bahwa siswa pada kelas kontrol dan kelas eksperimen mempunyai perbedaan hasil belajar pada materi sistem pencernaan manusia.

Pekanbaru, dapat disimpulkan bahwa penggunaan model pembelajaran Think Pair Share (TPS) berbantuan media 
standing banner berpengaruh terhadap hasil belajar siswa pada materi sistem pencernaan manusia kelas XI IPA 2 SMAN 16 Pekanbaru TP. 2018/2019.

\section{SARAN}

Bedasarkan pembahasan hasil penelitian dan kesimpulan maka peneliti mengajukan beberapa saran yang berhubungan dengan penggunaan model Think Pair Share (TPS) yakni sebagai berikut:

a. Guru harus benar-benar menguasai kelas kerena banyak kelompok yang akan lapor dan perlu dimonitor.

b. Harus menyediakan sumber belajar yang banyak karena pada saat suasana diskusi akan sedikit ide atau gagasan yang muncul pada siswa karena mereka hanya berdua atau berpasangan.

c. Media standing banner harus didesain sedemikian rupa untuk menarik perhatian siswa saat proses belajar mengajar berlangsung.

\section{DAFTAR PUSTAKA}

Adji. (2015). Sistem Pencernaan pada Manusia. Tersedia Online. Https://Slideplayer.Info/Slide/2
866875/. [10 November 2018. Pukul 10.30 WIB]

Arikunto, S. (2011).Prosedur Penelitian. Bumi Aksara: Jakarta.

Arsyad, A. (2014). Media Pembelajaran. PT Raja Grafindo Persada: Jakarta

Dimyati \& Mudjiono. (2013). Belajar dan Pembelajaran. Rineka Cipta: Jakarta.

Handayani, W, C. (2017). Pengaruh Pembelajaran TPS Terhadap Hasil Belajar Ditinjau Dari Keterampilan Berkomunikasi. Jurnal Ilmiah Pendidikan IPA. Volume 4 No 2.

Hamalik.(2001). Proses Belajar Mengajar. Bumi Aksara: Bandung

Ibrahim, M. (2000). Pembelajaran kooperatif. Surabaya University Press: Surabaya

Kresnoadi. (2018). Gangguan pada Organ Pencernaan Manusia. Tersedia online https://blog.ruangguru.com/gan gguan-organ-pencernaanmanusia.[10 November 2018. Pukul 10.30 WIB]

Meltzer, D.E. (2002). “The Relationship Between Matematic Preparation And Conceptual Learning Gains In Physien: A Possible "Hidden Variabel " In Diagnostic Pretest Score “" American Journal Of Physics. Vol. 70. No 7. Hal 120-137

Purwanto. (2009). Evaluasi hasil belajar. Pustaka belajar: Yogyakarta. 
Pratiwi, D. (2016). Pengenalan Pengolahan Sampah Untuk Anak-Anak Taman KanakKanak Melalui Media Banner. Bioedukasi Jurnal Pendidikan biologi.Vol. 7. No 1.

Sardiman.(2014). Interaksi dan Motivasi Belajar Mengajar. Raja Grafindo Persada Media Jakarta.

Sugiyono.(2015). Statistika untuk Penelitian. Alfabeta: Bandung.

Sugiyono.(2009) Metode Penelitian Pendidikan.Alfabeta Bandung.

Sudjana, N. (2009). Penilaian Hasil Proses Belajar Mengajar Remaja. Rosdakarya: Bandung.

Suraya, Subagia \& Tika. (2014).

Pengaruh Model Pembelajaran Think Pair Share Terhadap Hasil Belajar Ipa Ditinjau Dari Keterampilan Berpikir Kritis
Siswa. E-Journal Program

Pascasarjana Universitas

Pendidikan Ganesha Program Studi IPA. Volume 4.

Slameto.(2010). Belajar dan Faktor-

Faktor Yang Mempengaruhi.

Rineka Cipta: Jakarta.

Shabrina, A. (2018). Memahami Fungsi dan Anatomi Sistem Pencernaan Manusia. Tersedia online. https://hellosehat.com/hidupsehat/anatomi-sistempencernaan/. [20 November 2018. Pukul 13.00 WIB]

Tatang (2012).Ilmu Pendidikan.Pustaka Setia: Bandung

Trianto. (2011). Mendesain

Pembelajaran Inovatif

Progresif. Kencana: Jakarta.

Trianto.(2010). Mendesain Model Pembelajaran Inovatif Progresif. Kencana Prenada Media Group: Jakarta. 